\title{
MicorRização, Nodulação E Produção da SoJa Roundup REAdY Após a Aplicação de Diferentes Formulações de Glyphosate ${ }^{1}$
}

\author{
Mycorrhizal Colonization, Nodulation and Yield of Roundup Ready Soybeans after Applying \\ Different Formulations Glyphosate
}

REIS, M.R. ${ }^{2}$, REIS, R.M. ${ }^{2}$, ALMEIDA, W.L. ${ }^{2}$, CARVALHO, A.M.X. ${ }^{2}$, RONCHI, C.P. ${ }^{2}$ e DIAS, R.C. ${ }^{2}$

\begin{abstract}
RESUMO - Objetivou-se neste trabalho avaliar o efeito de diferentes formulações à base de glyphosate sobre a colonização micorrizica e nodulação no cultivar de soja RR TMG 125 . Os experimentos foram desenvolvidos em condições de campo, em Latossolo Vermelho-Amarelo, durante os anos agrícolas 2010/2011 e 2011/2012. Os tratamentos constaram da aplicação da dose de 720 g e.a. ha ${ }^{-1}$ das seguintes formulações de glyphosate: Trop ${ }^{\circledR}$, Roundup Original ${ }^{\circledR}$, Roundup Ultra ${ }^{\circledR}$, Roundup WG ${ }^{\circledast}$, Roundup Transorb $\mathrm{R}^{\circledR}$ e Zapp Qi ${ }^{\circledR}$, além de duas testemunhas (capinada e não capinada). Utilizou-se o delineamento em blocos casualizados com quatro repetições. A matéria seca da parte aérea, nodulação e produtividade de soja não foram influenciadas pelas diferentes formulações de glyphosate. Para a colonização micorrízica, observou-se efeito positivo da formulação Roundup Original ${ }^{\circledR}$, em relação à testemunha capinada; no entanto, esse efeito não foi contínuo nos dois anos de experimento. A variável número de nódulos foi mais afetada pelas formulações de glyphosate testadas.
\end{abstract}

Palavras-chave: fixação de $\mathrm{N}_{2}$ fungos micorrízicos, Glycine max, plantas daninhas.

\begin{abstract}
The aim of this study was to evaluate the effect of different glyphosate-based formulations on mycorrhizal colonization and nodulation in soybean cultivar RR TMG 125. The experiments were conducted under field conditions in Red-Yellow Latosol, during 2010/2011 and 2011/2012. The formulations Trop ${ }^{\circledR}$, Roundup Original ${ }^{\mathbb{B}}$, Roundup Ultra ${ }^{\mathbb{R}}$, Roundup $W G^{\circledR}$, Roundup Transorb $R^{\mathbb{B}}$ and ZappQi $i^{\mathbb{B}}$ were used at a glyphosate dose of $720 \mathrm{~g}$ a.e. ha $\mathrm{H}^{-1}$. The experiment was arranged in a randomized block design with four replications and two controls (hoed control and non-hoed control). The variables shoot, nodule dry matter, and soybean yield were not influenced by the different formulations of glyphosate. For mycorrhizal colonization, it was verified that a positive effect of the herbicide Roundup Original ${ }^{\mathbb{B}}$ regarding the hoed control was not continuous in the two years of the experiment. The variable number of nodules was the most affected by the glyphosate formulations tested.
\end{abstract}

Keywords: $\mathrm{N}_{2}$ fixation, mycorrhizal fungi, Glycine max, weeds.

\section{INTRODUÇÃO}

Desde o ano de 2004, o cultivo de soja transgênica resistente ao glyphosate Roundup Ready vem se expandindo em todo o Brasil, assim como a utilização desse herbicida. Atualmente, essa variedade representa aproximadamente $85 \%$ da área cultivada com soja no País, sendo o manejo de plantas daninhas realizado basicamente com aplicações sequenciais de glyphosate (Conab, 2012).
O glyphosate atua na rota do ácido chiquímico, a qual produz compostos fundamentais para o desenvolvimento vegetal. Os principais produtos da rota são compostos fenólicos, que podem representar até 35\% da biomassa vegetal (Boudet et al., 1985). O glyphosate inibe a enzima EPSPs (5enolpiruvilshiquimato-3-fosfato sintase), evitando a transformação do shiquimato em corismato. Os principais produtos que derivam do corismato são os aminoácidos aromáticos

Recebido para publicação em 4.7.2013 e aprovado em 6.12.2013.

2 Universidade Federal de Viçosa, Viçosa-MG, Brasil, <marceloreis@ufv.br>.

Planta Daninha, Viçosa-MG, v. 32, n. 3, p. 563-569, 2014 
tirosina, fenilalanina e triptofano. No caso da soja resistente ao glyphosate, a tolerância ao herbicida foi obtida pela inserção de um gene (AroA) oriundo do genoma da Agrobacterium sp., estirpe $\mathrm{CP} 4$, que codifica uma enzima-alvo insensivel ao glyphosate (CP4-EPSPs). Na planta, a CP4-EPSPs proporciona um by-pass na rota do shiquimato, o que permite à rota funcionar normalmente mesmo quando a enzima nativa é inibida pelo glyphosate (Dill et al., 2008; Velini et al., 2009).

O impacto do glyphosate sobre os microrganismos simbiontes radiculares tem sido questionado devido à grande importância desses agentes biológicos na nutrição e sanidade da cultura da soja. A fixação biológica do nitrogênio (FBN) é um dos principais fatores bióticos que contribuem para a elevada produção de soja, uma vez que a demanda de nitrogênio dos cultivares brasileiros pode ser suprida exclusivamente pelo processo biológico, por meio da inoculação com estirpes selecionadas de Bradyrhizobium japonicum e B. elkani, podendo significar para o Brasil uma economia significativa de fertilizantes nitrogenados (Marenco et al., 1993; Hungria et al., 2001).

Os fungos micorrízicos arbusculares (FMAs) são simbiontes comuns das raízes das plantas. Eles atuam como um sistema radicular adicional, responsáveis principalmente pelo incremento na absorção de nutrientes em geral, sobretudo o fósforo (P) (Smith \& Read, 2008). Essa contribuição é particularmente importante nos solos ácidos e de baixa fertilidade, como os de cerrado, considerados solos "drenos" de P, ou seja, solos em que o processo de fixação do $\mathrm{P}$ em formas não lábeis restringe o acesso do sistema radicular das plantas ao $\mathrm{P}$ retido no solo (Novais \& Smyth, 1999; Miranda et al., 2005).

Embora o efeito do glyphosate sobre associação micorrízica da soja já tenha sido estudado por Morandi (1989), Mujica et al. (1999), Malty et al. (2006) e Reis et al. (2010), os resultados são controversos e não elucidam se esse efeito pode estar ligado às diferentes formulações do produto. Formulações comerciais diferentes podem estar associadas a adjuvantes diferentes, ou vias de sintese química diferentes, alterando a ação dos herbicidas, que podem também, assim como os adjuvantes, afetar os microrganismos (Malkones, 2000). Esse efeito já foi verificado, por exemplo, entre diferentes formulações comerciais de glyphosate sobre bactérias fixadoras de nitrogênio associadas à soja RR, podendo estar associado aos adjuvantes ou ao tipo de sal presentes nas formulações (Reddy \& Zablotowicz, 2003; Santos et al., 2007).

Dessa forma, objetivou-se, neste trabalho, avaliar o efeito de diferentes formulações comerciais de glyphosate sobre a colonização micorrízica e nodulação de soja Roundup Ready (TMG 125).

\section{MATERIAL E MÉTODOS}

Os experimentos foram conduzidos em campo, na Estação Experimental da COOPADAP (Cooperativa Agropecuária do Alto Paranaíba), localizada no município de Rio Paranaíba, Minas Gerais (longitude de 46 09' 46' 'W, latitude de $19^{\circ} 12^{\prime} 26^{\prime \prime}$ S e altitude de $1.159 \mathrm{~m}$ ), durante os meses de novembro a abril, nos anos agrícolas de 2010/11 e 2011/12. O solo da área experimental é classificado como Latossolo Vermelho-Amarelo, com textura argilosa e relevo plano. Uma amostra composta do solo da área experimental foi retirada, antes da instalação do experimento, para caracterização química, conforme Silva (2009). As características químicas do solo eram: $\mathrm{pH}$ em água de 5,$90 ; 12,40 \mathrm{mg} \mathrm{dm}^{-3}$ de $\mathrm{P}$ disponivel (Mehlich-1); $129 \mathrm{mg} \mathrm{dm}^{-3}$ de $\mathrm{K}$ trocável (Mehlich-1); 2,60 $\mathrm{cmol}_{\mathrm{c}} \mathrm{dm}^{-3}$ de Ca trocável; $0,80 \mathrm{cmol}_{\mathrm{c}} \mathrm{dm}^{-3}$ de $\mathrm{Mg}$ trocável; $1,50 \mathrm{dag} \mathrm{kg}^{-1}$ de matéria orgânica; acidez potencial $(\mathrm{H}+\mathrm{Al})$ de $2,81 \mathrm{cmol}_{\mathrm{c}} \mathrm{dm}^{-3}$; e CTC total de $6,54 \mathrm{cmol}_{\mathrm{c}} \mathrm{dm}^{-3}$.

Aos 15 dias antes da semeadura da soja, a área experimental foi dessecada com uma mistura de glyphosate + 2,4 D (1.440 + $470 \mathrm{~g} \mathrm{ha}^{-1}$ ). A adubação mineral foi realizada no sulco de plantio, de forma semelhante à dos cultivos comerciais da região, constituindo-se de $300 \mathrm{~kg} \mathrm{ha}^{-1}$ do formulado NPK 2-20-20.

As sementes do cultivar de soja TMG 125 RR foram tratadas com o fungicida thiophanatemethyl $\left(0,625 \mathrm{~g} \mathrm{~kg}^{-1}\right.$ de sementes) e inoculadas com estirpes de Bradyrhizobium japonicum SEMIA 5079 e SEMIA $5080\left(9 \times 10^{9}\right.$ células 
viáveis $\mathrm{kg}^{-1}$ de sementes). A semeadura foi feita no espaçamento entre linhas de $50 \mathrm{~cm}$, com densidade de 14 plantas por metro, a uma profundidade de $5 \mathrm{~cm}$. Posteriormente à semeadura, foram demarcadas parcelas de $5,0 \times 2,5 \mathrm{~m}$. Foram utilizadas as formulações Roundup Original ${ }^{\circledR}$, Trop ${ }^{\circledR}$, Roundup Ultra ${ }^{\circledR}$, Roundup $\mathrm{WG}^{\circledR}$, Roundup Transorb $\mathrm{R}^{\circledR}$ e Zapp $\mathrm{QI}^{\circledR}$, todas aplicadas na dose de $720 \mathrm{~g}$ e.a. ha ${ }^{-1}$ de glyphosate. Além disso, foram mantidas duas testemunhas (capinada e não capinada). O delineamento experimental foi em blocos casualizados com quatro repetições.

Uma única aplicação dos herbicidas foi realizada aos 25 dias após a semeadura da soja (estádio $\mathrm{V}_{2}-\mathrm{V}_{3}$ ). Utilizou-se de um pulverizador costal pressurizado a $\mathrm{CO}_{2}$, operando à pressão constante de $3,0 \mathrm{kgf} \mathrm{cm}^{-2}$, equipado com barra de quatro pontas tipo leque 110.03 espaçadas de $50 \mathrm{~cm}$, a uma altura de aproximadamente $60 \mathrm{~cm}$ em relação ao solo e com volume de calda equivalente a $150 \mathrm{~L} \mathrm{ha}^{-1}$.

Os dados climáticos diários de precipitação, umidade relativa e temperatura durante os experimentos foram adquiridos da estação meteorológica da Universidade Federal de Viçosa, campus Rio Paranaíba, localizada próxima da área experimental (Figura 1). No manejo de pragas da cultura utilizaram-se os inseticidas flubendiamide $\left(24 \mathrm{~g} \mathrm{ha}^{-1}\right)$, betacyfluthrin $\left(10 \mathrm{~g} \mathrm{ha}^{-1}\right)+$ imidacloprid $\left(80 \mathrm{~g} \mathrm{ha}^{-1}\right)$ e novaluron $\left(5 \mathrm{~g} \mathrm{ha}^{-1}\right)$ para o controle da lagarta-da-soja (Anticarsia gemmatalis) e dos percevejos Nezara viridula, Piezodorus guildinii $e$ Euschistus heros. No controle da ferrugem da soja (Phakopsora pachyrhizi), utilizou-se o fungicida cyproconazole + picoxystrobin $\left(24+60 \mathrm{~g} \mathrm{ha}^{-1}\right)$.

Quando a soja atingiu o estádio $\mathrm{R}_{2}$ (florescimento pleno), coletaram-se quatro plantas de cada parcela, para determinação da matéria seca da parte aérea e colonização micorrizica das raízes por fungos micorrízicos arbusculares nativos. A colonização radicular por fungos micorrízicos foi avaliada pelo método da intersecção em placa reticulada (Giovannetti \& Mosse, 1980), após as raízes serem descoradas em solução $\mathrm{KOH} 10 \%$ e coradas com azul de tripano 0,05\% em lactoglicerol (Brundrett et al., 1996). Os resultados foram expressos em porcentagem do comprimento de raízes colonizadas por fungos micorrízicos arbusculares.

$\mathrm{Na}$ avaliação da matéria seca da parte aérea, as plantas amostradas foram secas em estufa de circulação forçada de ar à temperatura de $72{ }^{\circ} \mathrm{C}$, até atingirem massa constante. Também em estufa, as sementes de soja coletadas foram secas, corrigindo-se o teor de umidade para $13 \%$, para avaliação de produtividade de sementes. A área útil de coleta de grãos foi de $6,25 \mathrm{~m}^{2}$ centrais da parcela.

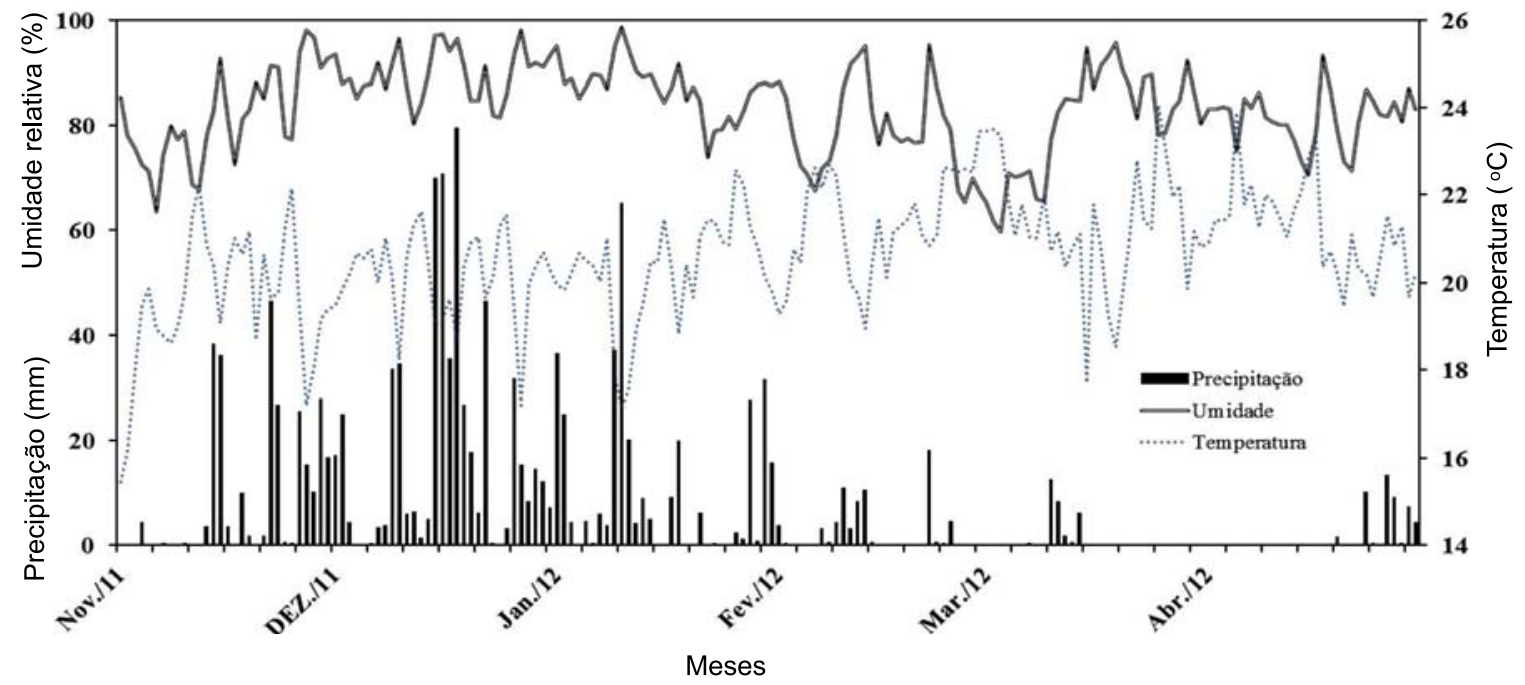

Figura 1 - Precipitação, umidade relativa e temperatura durante os meses de condução do experimento (novembro/2010 a abril/2011) e no segundo ano de avaliação (novembro/2011 a abril/2012). 
No segundo ano de experimento (2011/12), acrescentou-se a avaliação da nodulação do sistema radicular de soja pelo número e massa seca de nódulos. Nesse caso, foram coletadas oito plantas de soja no estádio $\mathrm{R}_{2}$ por parcela experimental. O sistema radicular das plantas foi extraído com auxílio de uma pá de corte, removendo-se um bloco de solo com aproximadamente $20 \mathrm{~cm}$ de profundidade no entorno das plantas, região onde se concentra a maior parte das raízes. Todo o volume de solo coletado e raízes das plantas foram lavados em água corrente sobre peneira com malha de $1,43 \mathrm{~mm}$. Na estimativa da nodulação, os nódulos foram contados e submetidos à secagem em estufa de circulação forçada de ar a $60{ }^{\circ} \mathrm{C}$ por 72 horas.

Quando atendidas as pressuposições para tal (normalidade dos erros, avaliada pelo teste de Bera-Jarque, e homogeneidade das variâncias, avaliada pelo teste de Bartlett), os dados foram submetidos à análise de variância pelo teste F. As médias dos tratamentos, em cada ano de avaliação, foram comparadas com o tratamento controle (capina manual) pelo teste de Dunnett $(\mathrm{p}<0,05)$ e, ao final, as médias dos tratamentos dos dois anos de experimento foram comparadas entre si pelo teste de Newman-Keuls $(\mathrm{p}<0,05)$. Como as avaliações de nodulação foram feitas apenas no segundo ano de experimento, as médias dos tratamentos foram comparadas apenas pelo teste de Dunnett $(\mathrm{p}<0,05)$.

\section{RESULTADOS E DISCUSSÃO}

As diferentes formulações comerciais de glyphosate, na dose de 720 g e.a. ha-1 ${ }^{-1}$ não afetaram a colonização micorrízica (MIC) das plantas de soja no primeiro ano de experimento (Tabela 1). Em trabalho realizado por Reis et al. (2010), em condições de campo, a aplicação única de glyphosate e a aplicação sequencial aos 15,30 e 45 DAE (1.080 g e.a. ha-1) não afetaram a MIC de soja tratada ou não com a mistura endossulfan + tebuconazole. No segundo ano $(2011 / 12)$, as parcelas que receberam aplicação da formulação Roundup Original ${ }^{\circledR}$ apresentaram maior MIC, em comparação à testemunha capina manual (Tabela 1).

Ressalta-se que apenas nas plantas tratadas com as formulações Roundup Original ${ }^{\circledR}$ e Roundup Ultra ${ }^{\circledR}$ a MIC foi equivalente nos dois anos de experimento; para as demais formulações, a MIC reduziu no segundo ano (Tabela 1). As formulações comerciais de glyphosate contêm componentes (adjuvantes) - geralmente, surfatantes - cuja finalidade é facilitar a absorção do glyphosate através da barreira da cutícula foliar. Alguns destes, como o grupo das etilaminas, são considerados

Tabela 1 - Matéria seca da parte aérea (MSPA), colonização micorrízica (MIC) e produtividade de soja Roundup Ready sob a aplicação de diferentes formulações de glyphosate ${ }^{\underline{1}}$, em duas safras consecutivas

\begin{tabular}{|c|c|c|c|c|c|c|c|c|c|}
\hline \multirow{2}{*}{ Tratamento } & \multicolumn{3}{|c|}{ MSPA (g) } & \multicolumn{3}{|c|}{$\mathrm{MIC}(\%)$} & \multicolumn{3}{|c|}{ Produtividade $\left(\mathrm{kg} \mathrm{ha}^{-1}\right)$} \\
\hline & ano 1 & ano 2 & média & ano 1 & ano 2 & média & ano 1 & ano 2 & média \\
\hline Capina manual & 7,38 & 10,31 & 8,85 & 83,4 a & $72,3 \quad b$ & 77,8 & 2613 & 2533 & 2573 \\
\hline Sem capina & 9,20 & 11,99 & 10,60 & 77,4 a & 75,3 a & 76,3 & $1536 *$ & $1291 *$ & $1413 *$ \\
\hline Roundup Original & 9,19 & 10,98 & 10,08 & 84,6 a & 82,0 a* & 83,3 & 2972 & 2665 & 2818 \\
\hline Trop & 9,21 & 11,16 & 10,19 & 81,2 a & $70,5 \quad b$ & 75,8 & 3247 & 2446 & 2846 \\
\hline Roundup Transorb R & 8,59 & 10,14 & 9,36 & 87,0 a & $71,8 \quad b$ & 79,4 & 2844 & 2568 & 2706 \\
\hline Zapp Qi & 9,21 & 12,02 & 10,62 & 83,4 a & $73,3 \quad b$ & 78,3 & 2927 & 2594 & 2761 \\
\hline Roundup Ultra & 8,13 & 10,24 & 9,18 & 83,5 a & 81,5 a & 82,5 & 3108 & 2446 & 2777 \\
\hline Roundup WG & 8,17 & 11,48 & 9,82 & 87,5 a & $69,3 \quad$ b & 78,4 & 2860 & 2564 & 2712 \\
\hline Média & $8,63 \mathrm{~b}$ & $11,04 \mathrm{a}$ & & 83,5 & 74,5 & & $2763 \mathrm{a}$ & $2388 \quad \mathrm{~b}$ & \\
\hline CV (\%) & \multicolumn{3}{|c|}{23,9} & \multicolumn{3}{|c|}{6,2} & \multicolumn{3}{|c|}{11} \\
\hline
\end{tabular}

${ }_{1}^{1}$ Médias seguidas por uma mesma letra minúscula na linha não diferem entre si pelo teste de Newman-Keuls a 5\% de probabilidade. Médias seguidas por um * diferem do tratamento testemunha capina manual pelo teste de Dunnett a 5\% de probabilidade. Quando a interação entre os fatores não foi significativa ( $>>0,10)$, os testes foram aplicados apenas com as médias marginais. 
significativamente mais tóxicos do que o glyphosate, causando sérias irritações em peixes e humanos (Amarante Junior et. al., 2002). No entanto, as formulações comerciais de glyphosate podem apresentar características diferenciadas na eficiência do produto como herbicida, bem como na toxicidade para plantas, microrganismos e humanos.

A matéria seca da parte aérea e a produtividade das plantas de soja não foram influenciadas pelas diferentes formulações de glyphosate, nos dois anos de experimento, em relação à testemunha capina manual (Tabela 1). Resultados semelhantes foram encontrados por Correia \& Durigan (2007), em que a aplicação de oito diferentes formulações comerciais de glyphosate (sete sais isopropilamina: Roundup Ready ${ }^{\circledR}$, Roundup Transorb $^{\circledR}$, Roundup Original ${ }^{\circledR}$, Polaris ${ }^{\circledR}$, Gliz $^{\circledR}$, Glifosato Nortox $^{\circledR}$ e Trop $^{\circledR}$; e um sal amônio: Roundup $\mathrm{WG}^{\circledR}$ ), na dose de 1.200 g e.a. ha- ${ }^{-1}$, não alterou o desenvolvimento vegetativo e reprodutivo das plantas de soja.

A interferência das plantas daninhas na cultura da soja mostrou-se muito efetiva na redução da produtividade da cultura. Nos experimentos, a interferência das plantas daninhas durante todo o ciclo da cultura (testemunha sem capina) reduziu a produtividade de soja em $45 \%$, em relação à testemunha capina manual (Tabela 1). Nepomuceno et al. (2007), estudando o período de interferência das plantas daninhas na cultura da soja nos sistemas de semeadura direta (SSD) e convencional (SSC), observaram que a interferência das plantas daninhas durante todo o ciclo da cultura reduziu a produtividade de grão de soja, em média, em 46\% no SSD e 32\% no SSC. Da mesma maneira, Silva et al. (2009) observaram redução no rendimento de grãos da soja em 73\% (áreas de baixa infestação), 82\% (área de média infestação) e 92,5\% (área de alta infestação).

$\mathrm{O}$ número de nódulos (NN) foi menor nos tratamentos com aplicações de Roundup Original $^{\circledR}$, Zapp Qi ${ }^{\circledR}$ e Roundup Ultra ${ }^{\circledR}$, em relação à testemunha capinada (Figura 2A). Os herbicidas Trop ${ }^{\circledR}$, Roundup Transorb $\mathrm{R}^{\circledR} \mathrm{e}$ Roundup $\mathrm{WG}^{\circledR}$ mostraram resultados intermediários, com tendência a menores NN, comparados aos da testemunha capinada.

A matéria seca de nódulos (MSN) não foi alterada pelas formulações de glyphosate, em comparação com a testemunha capinada (Figura 2B). Entre os parâmetros utilizados na avaliação da nodulação, a MSN apresenta melhor correlação com o desempenho simbiótico, além de maior praticidade e menor
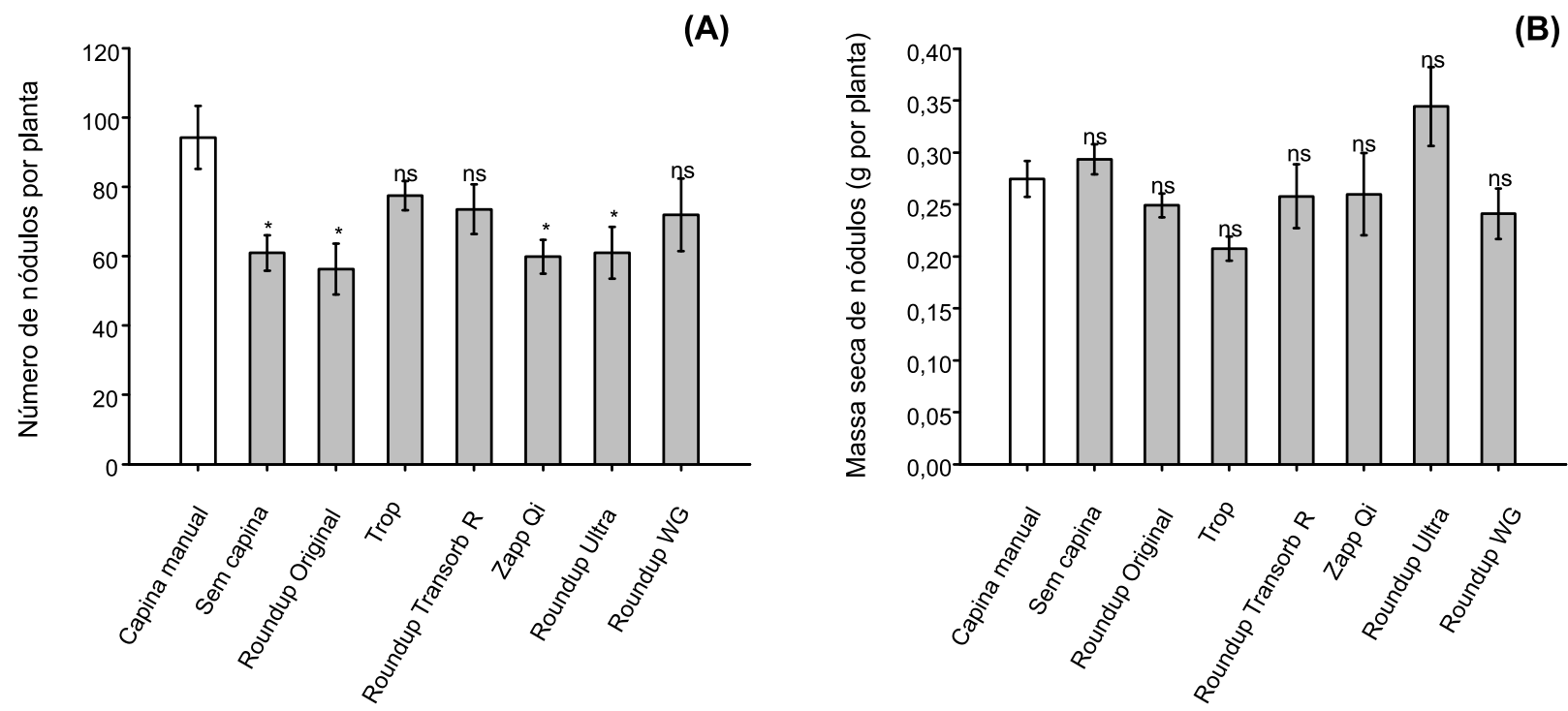

Figura 2 - Número de nódulos por planta (A) e matéria seca de nódulos (B) em plantas de soja tratada com diferentes formulações de glyphosate. (ns) não significativo ou (*) significativamente diferente da testemunha capina manual pelo teste de Dunnett a 5\% de significância. As barras correspondem ao erro-padrão das médias. 
variabilidade espacial e temporal (Bohrer \& Hungria, 1998). De acordo com Souza et al. (2008), a MSN e MSPA de plantas coletadas no estádio $R_{2}$ constituem o conjunto mínimo de parâmetros para a avaliação da fixação biológica de nitrogênio na cultura da soja. Resultados semelhantes foram encontrados por Dvoranen et al. (2008), quando constataram que o glyphosate em aplicação única ou sequencial (540 e 360 g e.a. ha ${ }^{-1}$ ) não reduziu a MSN em plantas de soja BRS 254 RR cultivadas em casa de vegetação. Da mesma maneira, Reis et al. (2010), em trabalho realizado com aplicação de glyphosate e fomesafen + fluazifop- $\rho$-butil, também não observaram redução na matéria seca de nódulos.

Nas condições deste trabalho, considerase que as formulações de glyphosate estudadas (Trop $^{\circledR}$, Roundup Original ${ }^{\circledR}$, Roundup Ultra ${ }^{\circledR}$, Roundup $\mathrm{WG}^{\circledR}$, Roundup Transorb $\mathrm{R}^{\circledR}$ e Zapp $\left.\mathrm{Qi}^{\circledR}\right)$ não apresentam efeitos negativos na nodulação e colonização micorrízica de soja RR cultivar TMG 125. Das variáveis analisadas, o número de nódulos foi a mais afetada pelas formulações de glyphosate. Tendo em vista os diferentes sais de glyphosate e adjuvantes presentes nas formulações comerciais, tornase importante a continuidade desse tipo de estudo, a fim de proporcionar melhor esclarecimento da interferência de formulações em cultivares de soja e na interação dessas com microrganismos endossimbiontes.

\section{AGRADECIMENTOS}

À Fundação de Amparo à Pesquisa do Estado de Minas Gerais (FAPEMIG), pelo apoio financeiro, e à Cooperativa Agropecuária do Alto Paranaíba (COOPADAP), por disponibilizar a área experimental.

\section{LITERATURA CITADA}

BOHRER, T. R. J.; HUNGRIA, M. Avaliação de cultivares de soja à fixação biológica do nitrogênio. Pesq. Agropec. Bras., v. 33, n. 6, p. 937-952, 1998.

BOUDET, A. M.; GRAZIANA, A.; RANJEVA, R. In: VAN SUMERE, C. F.; LEA, P. J. The biochemistry of plant phenolics. Oxford: Clarendon Press, 1985. 135 p.

BRUNDRETT, M. C. et al. Working with mycorrhizas in forest and agriculture. Camberra: Pirie, 1996. 374 p.
COMPANHIA NACIONAL DE ABASTECIMENTO CONAB. Safras. Disponível em: <http://www.conab.gov.br/ OlalaCMS/uploads/arquivos/12_03_13_11_04_08_boletim_ marco_2012.pdf>. Acesso em: 7 jul. 2012.

CORREIA, N. M.; DURIGAN, J. C. Seletividade de diferentes herbicidas à base de glyphosate a soja RR. Planta Daninha, v. 25, n. 2, p. 375-379, 2007.

DILL, G. M.; CAJACOB, C. A.; PADGETTE, S. R. Glyphosate-resistant crops: adoption, use and future considerations. Pest Manag. Sci., v. 64, n. 4, p. 326-331, 2008.

DVORANEN, E. C. et al. Nodulação e crescimento de variedades de soja RR sob aplicação de glyphosate, fluazifopp-butyl e fomesafen. Planta Daninha, v. 26, n. 3, p. 619-625, 2008.

GIOVANNETTI, M.; MOSSE, B. An evaluation of techniques to measure vesicular-arbuscular mycorrhizal infection in roots. New Phytol., v. 84, n. 3, p. 489-490, 1980.

HUNGRIA, M.; CAMPO, R. J.; MENDES, I. C. Fixação biológica de nitrogênio na cultura da soja. Londrina: Embrapa Soja, 2001. 48 p. (Circular Técnica, 35).

MALKONES, H. P. Comparasion of the effects of differently formulated herbicides on soil microbial activities (review).

J. Plant Dis. Protec., v. 8, n. 5, p. 781-789, 2000.

MALTY, J. D. S. et al. Efeitos do glifosate sobre microrganismos simbiotróficos de soja, em meio de cultura e casa de vegetação. Pesq. Agropec. Bras., v. 41, n. 2, p. 285-291, 2006.

MARENCO, R. A.; LOPES, N. F.; MOSQUIM, P. R. Nodulation and nitrogen fixation in soybeans treated with herbicides. R. Bras. Fisiol. Veg., v. 5, n. 2, p. 121-126, 1993.

MIRANDA, J. C. C.; VILELA, L.; MIRANDA, L. N. Dinâmica e contribuição da micorriza arbuscular em sistemas de produção com rotação de culturas. Pesq. Agropec. Bras., v. 40, n. 10, p. 1005-1014, 2005.

MORANDI, D. Effect of xenobiotics on endomycorrhizal infection and isoflavonoid accumulation in soybean roots. Plant Physiol. Biochem., v. 27, n. 5, p. 697-701, 1989.

MUJICA, M. et al. Influence of the herbicides chlorsulfuron and glyphosate on mycorrhizal soybean intercropped with the weeds Brassica campestris or Sorghum halepensis. Symbiosis, v. 27, n. 1, p. 73-81, 1999.

NEPOMUCENO, M. et al. Períodos de interferência das plantas daninhas na cultura da soja nos sistemas de semeadura direta e convencional. Planta Daninha, v. 25, n. 1, p. 43-50, 2007. 
NOVAIS, F. R.; SMYTH, T. J. Fósforo em solo e planta em condições tropicais. Viçosa, MG: Universidade Federal de Viçosa, 1999. 399 p.

REDDY, K. N.; ZABLOTOWICZ, R. M. Glyphosateresistant soybean response to various salts of glyphosate and glyphosate accumulation in soybean nodules. Weed Sci., v. 51, n. 4, p. 496-502, 2003.

REIS, M. R. et al. Impactos do glyphosate associado com endossulfan e tebuconazole sobre microrganismos endossimbiontes da soja. Planta Daninha, v. 28, n. 1, p. 113-121, 2010.

SANTOS, J. B. et al. Avaliação de formulações de glyphosate sobre soja Roundup Ready. Planta Daninha, v. 25, n. 1, p. 165-171, 2007.
SILVA, A. F. et al. Período anterior à interferência na cultura da soja-RR em condições de baixa, média e alta infestação. Planta Daninha, v. 27, n. 1, p. 57-66, 2009.

SILVA, F. C. Manual de análises químicas de solos, plantas e fertilizantes. 2.ed. Brasília: Embrapa Informação Tecnológica, 2009. 627 p.

SMITH, S. E.; READ, D. J. Mycorrhizal Symbiosis. 3.ed. London: Academic Press, 2008. 803 p.

SOUZA, R. A. et al. Conjunto mínimo de parâmetros para avaliação da microbiota do solo e da fixação biológica do nitrogênio pela soja. Pesq. Agropec. Bras., v. 43, n. 1, p. 83-91, 2008.

VELINE, E. D. et al. Glyphosate. Botucatu: FEPAF, 2009. 496 p. 